\title{
Point-of-Care C-Reactive Protein Testing and Antibiotic Prescribing for Respiratory Tract Infections: A Randomized Controlled Trial
}

\author{
Jochen W. L. Cals, MD, $P b D^{1}$ \\ Marjolein J. C. Schot, MD, MSc' \\ Sanne A. M. de Jong, MD, MSc ${ }^{1}$ \\ Geert-Jan Dinant, MD, $P b D^{1}$ \\ Rogier M. Hopstaken, MD, PbD \\ 'Department of General Practice, School \\ for Public Health and Primary Care \\ (CAPHRI), Maastricht University Medical \\ Centre, Maastricht, The Netherlands \\ ${ }^{2}$ Foundation of Primary Health Care Centres \\ Eindhoven, Eindhoven, The Netherlands
}

\begin{abstract}
PURPOSE Antibiotics are only beneficial for subgroups of patients with acute lower respiratory tract infections (LRTI) and rhinosinusitis in family practice, yet overprescribing for these conditions is common. C-reactive protein (CRP) pointof-care testing and delayed prescribing are useful strategies to reduce antibiotic prescribing, but both have limitations. We evaluated the effect of CRP assistance in antibiotic prescribing strategies-including delayed prescribing-in the management of LRTI and rhinosinusitis.
\end{abstract}

METHODS We conducted a randomized controlled trial in which 258 patients were enrolled (107 LRTI and 151 rhinosinusitis) by 32 family physicians. Patients were individually randomized to CRP assistance or routine care (control). Primary outcome was antibiotic use after the index consultation. Secondary outcomes included antibiotic use during the 28-day follow-up, patient satisfaction, and clinical recovery.

RESULTS Patients in the CRP-assisted group used fewer antibiotics (43.4\%) than control patients (56.6\%) after the index consultation (relative risk [RR] $=0.77$; $95 \%$ confidence interval $[\mathrm{Cl}], 0.56-0.98)$. This difference remained significant during follow-up $(52.7 \%$ vs $65.1 \%$; RR $=0.81 ; 95 \% \mathrm{Cl}, 0.62-0.99)$. Delayed prescriptions in the CRP-assisted group were filled only in a minority of cases $23 \%$ vs $72 \%$ in control group, $P<.001)$. Recovery was similar across groups. Satisfaction with care was higher in patients managed with CRP assistance $(P=.03)$.

CONCLUSIONS CRP point-of-care testing to assist in prescribing decisions, including delayed prescribing, for LRTI and rhinosinusitis may be a useful strategy to decrease antibiotic use and increase patient satisfaction without compromising patient recovery.

Conflict of interest: Orion Diagnostica (Finland) is the funder of the study and is manufacturer of the QuikRead point-of-care C-reactive protein testing devices. Rogier Hopstaken bas received travel funds from Axis-Shield (Norway) and Orion Diagnostica (Finland), botb manufacturers of point-of-care C-reactive protein testing devices.

AC Annals Journal Club selection; see inside back cover or http://www. annfammed.org/AJC/.

\section{CORRESPONDING AUTHOR}

Jochen Cals, MD, PhD

Department of General Practice

Maastricht University

P.O. Box 616

6200 MD Maastricht

The Netherlands

j.cals@hag.unimaas.nl
Ann Fam Med 2010;8:124-133. doi:10.1370/afm.1090.

\section{INTRODUCTION}

$\mathrm{R}$ espiratory tract infections are among the most common reasons to consult in family practice. Although antibiotic treatment is considered necessary only for community-acquired pneumonia and for small subgroups of the other lower and upper respiratory tract infections, ${ }^{1-5}$ antibiotics are prescribed to roughly $80 \%$ of patients consulting for lower respiratory tract infection (LRTI) or acute rhinosinusitis. ${ }^{6,7}$ Signs and symptoms are of limited value in identifying those patients in need of antibiotic treatment for these conditions. ${ }^{2,8-10}$ Diagnostic uncertainty and patient-related factors, such as patient expectations and pressure, often lead to unjustified antibiotic prescribing by family physicians. ${ }^{11,12}$

C-reactive protein $(\mathrm{CRP})$ is an acute-phase protein with levels quickly rising during inflammatory processes. Currently, CRP can be measured by using a point-of-care test, which has been proved both accurate and robust in a family practice setting. ${ }^{13} \mathrm{~A}$ CRP value, combined with clinical 
parameters, increases diagnostic certainty ${ }^{14-16}$ and may thereby help identify those patients who will benefit from antibiotic treatment. Latest randomized evidence has shown that antibiotic prescribing rates fall significantly when using CRP tests within consultations for LRTI without compromising clinical outcomes. ${ }^{17}$ Similar effects are suggested for rhinosinusitis. ${ }^{18}$

Delayed prescriptions are prescriptions written under the condition that they are not used immediately but only if symptoms persist. ${ }^{19}$ Several studies in the United Kingdom found lower antibiotic use when introducing delayed prescribing. ${ }^{20-22}$ Most studies investigating delayed prescribing involved uncomplicated respiratory tract infection solely, thereby limiting generalization of the study results to the full range of patients. The delayed strategy does not help family physicians estimate illness severity and identify patients who may benefit from such a prescription. CRP testing may be of great use in this regard, because it helps to identify both low- and high-risk patients with an emphasis on ruling out respiratory tract infections that have a potentially complicated course. Nonetheless, interpreting and communicating intermediately elevated test results to patients is challenging, and patients with these values commonly return for further consultation. ${ }^{23,24}$ A delayed prescribing may provide an appropriate safety net for both patients and family physicians for patients with intermediately elevated CRP results.

We hypothesized that CRP testing within the consultation would help the physician to better triage patients into no prescription, delayed prescription, or immediate prescription strategies without compromising patient outcomes. We therefore conducted a randomized trial of CRP-assisted prescribing strategies for management of LRTI and rhinosinusitis.

\section{METHODS}

\section{Design}

The study was an open, individually randomized, controlled trial evaluating the effect of CRP assistance on the management of LRTI and rhinosinusitis.

\section{Patients and Setting}

A total of 33 family physicians working in 11 family practice centers in the southeastern part of the Netherlands participated in the study. The physicians recruited patients with LRTI or rhinosinusitis from November 2007 until April 2008. All patients aged 18 years and older who consulted for the first time for a current episode of LRTI or rhinosinusitis and met the defined inclusion criteria were eligible for the trial.

For LRTI ${ }^{15,17}$ patients made their first consultation for the current episode of cough (duration less than 4 weeks) regarded by the physician to be caused by an acute LRTI with at least 1 of following 4 focal signs and symptoms: (1) shortness of breath, (2) wheezing, (3) chest pain, and (4) auscultation abnormalities. At least 1 of the following systemic signs and symptoms had to be present: (1) fever, (2) perspiring, (3) headache, (4) myalgia, and (5) feeling generally unwell.

For rhinosinusitis ${ }^{2,25,26}$ patients made a first consultation for the current episode of rhinosinusitis (duration of less than 4 weeks) with at least 1 of the following symptoms: (1) history of rhinorrhea and (2) blocked nose. At least 1 of the following symptoms or signs had to be present: (1) purulent rhinorrhea, (2) unilateral facial pain, (3) headache, (4) teeth pain, (5) pain when chewing, (6) maxillary/frontal pain when bending over, or (7) worsening of symptoms after initial improvement.

Exclusion criteria included immediate requirement of admission to a hospital, no understanding of the Dutch language, previous participation in the study, antibiotic use or hospitalization in the past 2 weeks, and immunocompromised status. All patients gave written informed consent before inclusion.

\section{Clinical Evaluation at Baseline and Randomization}

The physicians performed a routine consultation, including a medical history and physical examination at their own discretion. They recorded inclusion criteria, signs, and symptoms, and they rated illness severity on a visual analogue scale (VAS). Once these criteria were recorded, randomization took place.

Each physician was provided with 1 pile of sequentially numbered opaque sealed envelopes (SNOSE). ${ }^{27}$ The use of this method prevents researchers, physicians, and patients from predicting and thus influencing which patient will be allocated to which intervention. The SNOSE pile per physician was prepared by a remote independent research team, using permuted block randomization to ensure similar enrollment in both groups. Different block sizes were chosen to prevent the allocation sequence from being anticipated. Patients were randomized into either the intervention or the control group.

For the intervention group (CRP assistance), CRP was measured by the practice nurse within the consultation and patients returned to the physician with the test result. The physician could use the CRP test result in addition to clinical assessment to decide on management (immediate, delayed, or no antibiotics).

For the control group (no CRP assistance), the physician had to decide on a management strategy (immediate, delayed, or no antibiotics) based on clinical assessment and finish the consultation (usual care). 
CRP was measured and recorded by the practice nurse after the consultation. Practice nurses were instructed not to communicate the test result to either physician or patient until after the study.

\section{C-Reactive Protein Point-of-Care Testing}

The CRP analysis was carried out using QuikRead CRP analyzers (Orion Diagnostica, Espoo, Finland). A CRP test result is available within 3 minutes after obtaining a drop of blood by finger prick. Validity and robustness have been established for primary care. ${ }^{13}$ Before the start of the study, the practice nurses were given a demonstration of the device by a product representative of Orion Diagnostica. Physicians were informed about the trial procedure and the evidencebased use of CRP testing during a 30-minute practice-based seminar given by the study team (J.C. or R.H.). In this seminar we stressed the additional value of using CRP values to rule out serious infection and emphasized that the test should always be used combined with clinical findings.

We advised not to prescribe antibiotics when CRP test results were less than $20 \mathrm{mg} / \mathrm{L}$, to give immediate antibiotics when CRP test results were greater than 100 $\mathrm{mg} / \mathrm{L}$, and to consider a delayed prescription when CRP levels were between 20 and $99 \mathrm{mg} / \mathrm{L}$. Physicians were allowed to deviate from the proposed prescribing strategies at any time. The cutoff points above were not presented as strict rules but solely as a recommendation, to be taken into account in combination with the clinical findings from medical history and physical examination when deciding on management. Cutoff points are based on previous diagnostic research and available evidence on CRP for respiratory tract infection. ${ }^{15,16,18,28}$ Physicians in the Netherlands are not familiar with CRP point-of-care testing, so a 4 -week run-in period enabled familiarization with the devices and interpretation of CRP test results before patient recruitment started.

If the physician decided to hand out a delayed prescription (to a patient in either the CRP-assisted or control group), the patient was informed about this strategy by the physician and was given an information sheet. The sheet described the delayed prescription strategy but did not indicate specific information on illness symptoms or the time to wait. This advice was left at the discretion of the physician. If required, the patient could collect the prescription at the practice front desk.

\section{Follow-up}

Patients were given a diary to fill out that included questions regarding reasons for consultation and symptoms during next 7 days. Each day patients rated symptoms cough, phlegm, shortness of breath, and sleeping problems (for LRTI); rhinorrhea, blocked nose, dental pain, headache, and pain at bending over (for rhinosinusitis); and disturbance of daily activities and general well-being (for both conditions) on a 7-point scale. The diary also included a Likert-scale question on satisfaction and the Patient Enablement Index, a measure of patients' ability in self-care. ${ }^{29}$ Patients handed in the diaries after 1 week. Patients who indicated they had not recovered from their illness on day 7 were contacted by the research team by telephone to follow up and record whether they had recovered on day 14 or day 28. After day 28 the electronic medical records were accessed from the physicians' databases to retrieve relevant information on antibiotic prescriptions, additional consultations, relevant comorbidity, and complications.

\section{Endpoints}

The primary outcome was antibiotic use after the index consultation (defined as those patients using antibiotics immediately and those filling a delayed prescription). Secondary outcomes were antibiotic use within 28-day follow-up (defined as any antibiotic use for the current respiratory tract infection within 28 days after the index consultation, including antibiotic use immediately after the index consultation); additional consultations; and patient satisfaction, enablement, and clinical recovery.

\section{Sample Size Calculation}

To calculate the needed sample size, we assumed that $40 \%$ of eligible patients would have LRTI and $60 \%$ would have rhinosinusitis. As reported prescribing rates for both conditions vary greatly (range 30\% to $80 \%)$ in large general practice database studies from the Netherlands, ${ }^{30-32}$ we decided to take a conservative approach by expecting 50\% prescribing in the control group. To detect a significant difference in antibiotic prescriptions of $20 \%$ (30\% in the intervention group vs $50 \%$ in the control group) for both clinical entities combined with $80 \%$ power at a $5 \%$ significance level and with the patient as unit of analysis, at least 188 patients (94 per group) would be required. Based on incidence figures from Dutch general practice and an estimated 5\% loss to follow-up, we aimed to recruit at least 200 patients within 1 winter period, for an estimated 80 LRTI patients and 120 rhinosinusitis patients.

\section{Statistical Analysis}

The primary analysis was intention to treat, and we assessed the effects of the intervention (CRP assistance) on antibiotic use after the index consultation compared with usual care (control group). Scores for each of the individual symptom items were added to create a total daily symptom score that ranged from $0 \%$ to $100 \%$ for LRTI patients and rhinosinusitis patients separately. Median daily symptom scores were 
plotted for the treatment groups and compared per day and for the full period. Differences were assessed using $\chi^{2}$ or the Mann-Whitney (Wilcoxon) $U$, where applicable. Exploratory analyses investigating the influence of patient and physician characteristics on the main effects were performed as sensitivity analyses. All analyses were performed with a multilevel approach using a 2-level logistic regression model to account and cor- rect for variation at the level of physician using a second-order penalized quasi-likelihood (PQL) approach. Results are presented as rates with corresponding $P$ values. Odds ratio obtained from the models were recalculated to relative risks. ${ }^{33}$ Analysis was performed using SPSS 15.0 (Statistical Package for the Social Sciences, SPSS, Inc, Chicago, Illinois) and MLwIN 2.0 (Centre for Multilevel Modelling, University of Bristol, Bristol, United Kingdom).

\section{Figure 1. Trial profile.}

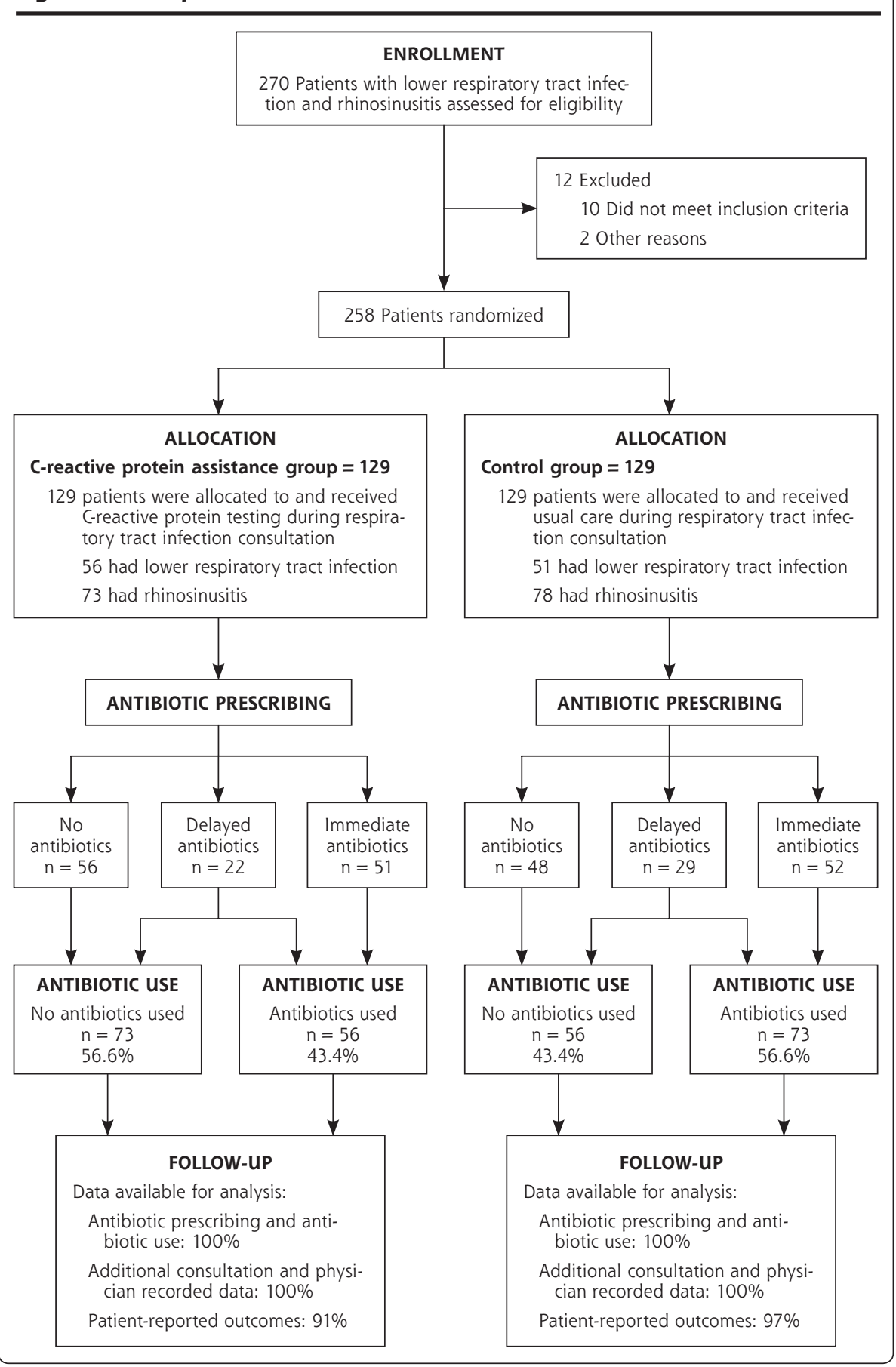

\section{Ethical Approval and Trial Registration}

The Ethics Committee of Catharina Hospital in Eindhoven, The Netherlands, approved this study. The CAPRESA trial (C-reactive protein Assisted Prescribing for RESpiratory tract infections to stimulate Antibiotic stewardship) was registered at The Netherlands National Trial Register, trial identifier NTR1112, and is reported following CONSORT guidelines for randomized controlled trials. ${ }^{34}$

\section{RESULTS}

\section{Patient Enrollment and Characteristics}

Thirty-two family physicians recruited patients for the trial. A total of 258 of whom 107 patients had acute LRTI, and 151 patients had acute rhinosinusitis. One hundred twenty-nine patients were randomized into the CRPassisted group (56 LRTI and 129 patients (51 LRTI and 78 rhinosinusitis) were randomized into the control group. Data for the primary outcome were available for all of these patients (Figure 1). Patient-reported outcomes patients were enrolled, and 73 rhinosinusitis), 
were available for $94 \%$ (243) of all recruited patients. The 2 groups were similar in terms of sex, age, educational level, comorbidity, and smoking history. Patient characteristics are shown in Table 1.

\section{C-Reactive Protein Point-of-Care Testing}

CRP test results at the index consultation were available for all patients. Median CRP was $17 \mathrm{mg} / \mathrm{L}$ in the CRP-assisted group and $19 \mathrm{mg} / \mathrm{L}$ in the control group $(P=.88)$. Table 2 displays the number of patients per CRP category, with 54.3\% of patients having a CRP level of less than $20 \mathrm{mg} / \mathrm{L}$. In the CRPassisted group, the CRP value was revealed to both patient and physician within the consultation in all 129 cases. As a result of logistical issues (eg, the patient was present in nurse's room when the CRP device displayed the test result), the CRP value was revealed to 13 patients in the control group, according to patient's self-reported diary data. Nonetheless, CRP testing in the control group was performed after the consultation with the physician, and the findings did not influence the physicians' prescribing decision. In 1 case a control patient's CRP result was revealed to the physician, with no implications for this patient's management.

\section{Effect on Antibiotic Prescribing}

Antibiotic use after the index consultation was recorded for $43.4 \%(n=56)$ of patients in the CRP-assisted group and for $56.6 \%$ $(n=73)$ of patients in the control group (relative risk $[\mathrm{RR}]=0.77$; 95\% confidence interval $[\mathrm{CI}]$, 0.56-0.98) (Table 3 and Figure 1). This difference in antibiotic use remained significant for the 28 -day follow-up period, $52.7 \%$ vs $65.1 \%$ ( $\mathrm{RR}=0.81,95 \% \mathrm{CI}, 0.62-0.99)$. At the index consultation, $39.5 \%$ $(\mathrm{n}=51)$ of the patients in the CRPassisted group received immediate antibiotics, whereas $43.4 \%(n=56)$ received no antibiotics, and $17.1 \%$ $(n=22)$ received a delayed prescrip- tion from their physician. In the control group $40.3 \%$ $(\mathrm{n}=52)$ received immediate antibiotics, $37.2 \%(\mathrm{n}=48)$ received no antibiotics, and $22.5 \%(n=29)$ received delayed antibiotics (Figure 1). Of those patients having received a delayed prescription in the control group $72.4 \%(\mathrm{n}=21)$ filled their delayed prescription in the following days compared with only $22.7 \%(n=5)$ in the CRP-assisted group $(P<.001)$.

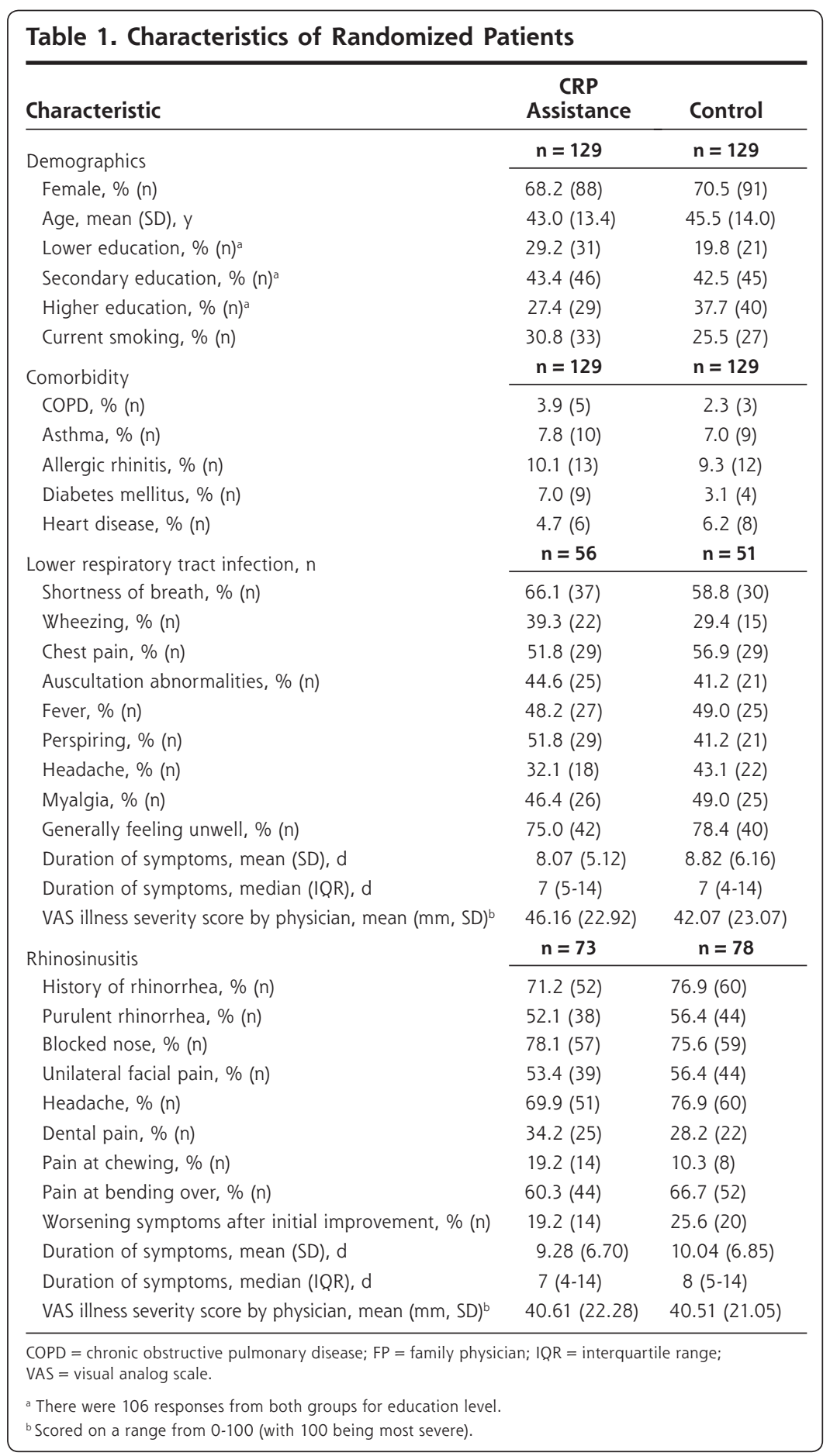




\begin{tabular}{|c|c|c|c|c|}
\hline CRP Measure & $\begin{array}{l}\text { All Patients } \\
n=258\end{array}$ & $\begin{array}{l}\text { CRP Assistance } \\
n=129\end{array}$ & $\begin{array}{l}\text { Control } \\
n=129\end{array}$ & $\begin{array}{c}P \\
\text { Value }^{a}\end{array}$ \\
\hline Mean (SD), mg/L & 34.17 (37.33) & 34.89 (38.41) & $33.46(36.36)$ & \\
\hline Median (IQR), mg/L & $18(<8-46)$ & $17(<8-52)$ & $19(<8-42)$ & .88 \\
\hline Minimum-maximum, mg/L & $<8->160$ & $<8->160$ & $<8->160$ & \\
\hline $0-20 \mathrm{mg} / \mathrm{L}, \%(\mathrm{n})$ & $54.3(140)$ & $56.6(73)$ & $51.9(67)$ & \\
\hline $21-50$ mg/L, \% (n) & $24.0(62)$ & $17.8(23)$ & $30.2(39)$ & \\
\hline $51-100$ mg/L, \% (n) & $14.3(37)$ & $17.1(22)$ & $11.6(15)$ & \\
\hline$>100$ mg/L, \% (n) & $7.4(19)$ & $8.5(11)$ & $6.2(8)$ & \\
\hline
\end{tabular}

Table 3. Effects of Intervention on Antibiotic Use After the Index Consultation (by CRP Category) and Within a 28-Day Follow-Up. Exploratory Data on Antibiotic Use Per Respiratory Tract Infection

\begin{tabular}{lllll}
\hline Antibiotic Use & $\begin{array}{c}\text { CRP Assistance } \\
\%(\mathbf{n})\end{array}$ & $\begin{array}{c}\text { Control } \\
\%(\mathbf{n})\end{array}$ & $\mathbf{R R}^{\mathbf{a}}$ & $\mathbf{9 5 \%} \mathbf{C l}$ \\
\hline After index consultation & $43.4(56 / 129)$ & $56.6(73 / 129)$ & 0.77 & $0.56-0.98$ \\
$\quad$ Rhinosinusitis & $45.2(33 / 73)$ & $60.3(47 / 78)$ & & \\
LRTI & $41.1(23 / 56)$ & $51.0(26 / 51)$ & & \\
Within 28-day follow-up & $52.7(68 / 129)$ & $65.1(84 / 129)$ & 0.81 & $0.62-0.99$ \\
Rhinosinusitis & $57.5(42 / 73)$ & $69.2(54 / 78)$ & & \\
LRTI & $46.4(26 / 56)$ & $58.8(30 / 51)$ & & \\
By CRP category & & & & \\
0-20 mg/L $(n=140)$ & $26.0(19 / 73)$ & $49.3(33 / 67)$ & & \\
21-50 mg/L $(n=62)$ & $56.5(13 / 23)$ & $59.0(23 / 39)$ & & \\
$51-100 \mathrm{mg} / \mathrm{L}(\mathrm{n}=37)$ & $68.2(15 / 22)$ & $66.7(10 / 15)$ & & \\
$>100 \mathrm{mg} / \mathrm{L}(\mathrm{n}=19)$ & $81.8(9 / 11)$ & $87.5(7 / 8)$ & & \\
\hline
\end{tabular}

$\mathrm{Cl}=$ confidence interval; $C R P=C$-reactive protein; $L R T I=$ lower respiratory tract infection; $R R=$ relative risk.

Note: Statistical testing was not performed on the exploratory data on antibiotic use per respiratory tract infec tions, as this trial was designed to detect differences between the total group of patients per group.

${ }^{a}$ Relative risks corrected for clustering

Table 3 also shows antibiotic use per CRP category for the 2 groups. The effect of use of CRP to guide antibiotic prescribing is most evident in the category of CRP values below $20 \mathrm{mg} / \mathrm{L}$, which comprises $54.9 \%$ $(\mathrm{n}=140)$ of all patients in this trial. In this large subgroup only $26 \%(n=19)$ of patients used antibiotics in the CRP-assisted group compared with $49.3 \%(\mathrm{n}=33)$ in the control group $(\mathrm{RR}=0.53 ; 95 \% \mathrm{CI}, 0.30-0.85)$.

Those patients actually using antibiotics after the index consultation in the CRP-assisted group had significantly higher median CRP values $\left(34 \mathrm{mg} / \mathrm{L}_{i}\right.$ interquartile range $[\mathrm{IQR}], 17-70)$ than those patients using antibiotics in the control group $\left(22 \mathrm{mg} / \mathrm{L}_{i} \mathrm{IQR},<8-48\right.$, $P=.04)$.

\section{Sensitivity Analyses}

In a prespecified exploratory analysis, we investigated whether demographic factors, case-mix, and relevant comorbidities affected the shown effect of CRP assistance on antibiotic prescribing. Inclusion of these variables in a logistic model as a sensitivity analysis of the primary endpoint did not alter the shown effect of CRP within LRTI and rhinosinusitis consultations. Moreover, to account and correct for variation at the level of the physician, we performed an additional multilevel analysis of the primary comparison. The effect of the intervention on antibiotic use after the index consultation ( $\mathrm{RR}=0.75 ; 95 \% \mathrm{CI}, 0.54-0.97)$ and within the follow-up period $(\mathrm{RR}=0.79 ; 95 \% \mathrm{CI}, 0.60-0.99)$ remained significant.

\section{Clinical Recovery}

The interventions had no discernible effect on recovery, resulting in comparable median daily symptom scores for intervention and control group for LRTI and rhinosinusitis. Recovery slopes are presented as median symptom scores per day in Figure 2. Of all patients, 22.9\% felt fully recovered on day 7 in the CRP-assisted group compared with $24.8 \%$ in the control group $(P=.73)$. Median patient reported time to full recovery (self-assessment) was comparable across the groups for both conditions (Table 4). Although this trial was not designed to assess safety, there were no serious adverse events (death or hospitalization).

\section{Additional Consultations, Satisfaction, and Enablement}

Additional consultations, either initiated by the patient or the physician, occurred in about 1 of 4 patients in the CRP-assisted group, with slightly lower, yet nonsignificant rates, for the control group (Table 4). Patients' intention to reconsult with future similar symptoms was higher in the group using CRP assistance, with $75 \%$ of patients indicating that they would return to their physician with similar symptoms compared with $61 \%$ in the control group $(P=.02)$. Overall, satisfaction with the index consultation was high, however, satisfaction scores were higher for patients in the CRPassisted group within the consultation $(P=.03)$. The 
Figure 2. Median symptom scores per group during first week after index consultation.

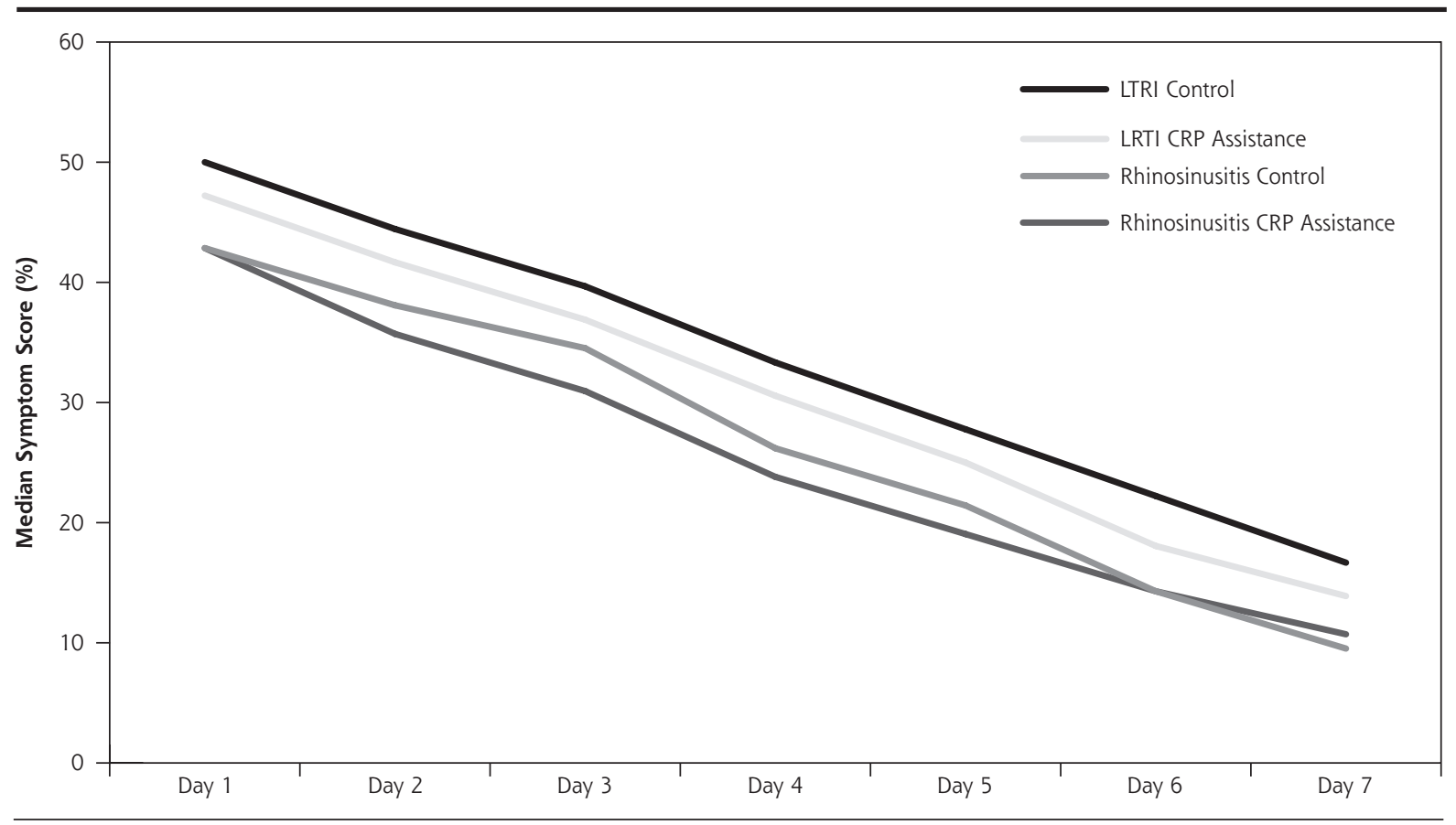

$\mathrm{CRP}=\mathrm{C}$-reactive protein; $\mathrm{LTRI}=$ lower respiratory tract infection

Symptom scores for LRTI were calculated by summing and deriving percentage total scores for 6 symptoms: cough, phlegm, sleeping problems, dyspnea, degree of illness, and limitations in daily activities. Symptom scores for rhinosinusitis were calculated by summing and deriving percentage total scores for 7 symptoms: rhinorrhea, blocked nose, dental pain, headache, pain at bending over, degree of illness, and limitations in daily activities.

Median symptom scores of intervention and control groups were not significantly different at any day in week 1 , nor when analyzed using area under the curve.

Table 4. Effects of Interventions on Patient-Reported Recovery and Secondary Outcomes (Assessed After the Index Consultation)

\begin{tabular}{|c|c|c|c|}
\hline Outcomes & $\begin{array}{c}\text { CRP } \\
\text { Assistance }\end{array}$ & Control & $\begin{array}{l}P \\
\text { Value }^{a}\end{array}$ \\
\hline \multicolumn{4}{|l|}{ Lower respiratory tract infection } \\
\hline Patients feeling recovered on day $7, \%(n / n)$ & $23.5(12 / 51)$ & $18.4(9 / 49)$ & .53 \\
\hline \multicolumn{4}{|l|}{ Patient reported time to full recovery } \\
\hline Median (IQR) & $15.5(9.5-28)$ & $20(13.3->28)$ & .21 \\
\hline Mean (SD) & $17.5(9.2)$ & $19.8(9.5)$ & \\
\hline \multicolumn{4}{|l|}{ Rhinosinusitis } \\
\hline Patients feeling recovered on day $7, \%(n / n)$ & $22.4(15 / 67)$ & $28.9(22 / 76)$ & .37 \\
\hline \multicolumn{4}{|l|}{ Patient reported time to full recovery, $h$} \\
\hline Median (IQR) & $14(10-28)$ & $14(7->28)$ & .77 \\
\hline Mean (SD) & $17.3(9.3)$ & $16.6(9.9)$ & \\
\hline \multicolumn{4}{|l|}{ All patients $(n=258)$} \\
\hline Reconsult, \% (n/n) & $25.6(33 / 129)$ & $17.8(23 / 129)$ & .13 \\
\hline $\begin{array}{l}\text { Satisfaction: patient at least very satisfied, } \\
\%(n / n)\end{array}$ & $76.3(90 / 118)$ & $63.2(79 / 125)$ & .03 \\
\hline $\begin{array}{l}\text { Future consultation intention: patient likely } \\
\text { to reconsult, } \%(n / n)\end{array}$ & $74.8(86 / 115)$ & $61.0(75 / 123)$ & .02 \\
\hline Patient enablement score ${ }^{b}$ & & & .58 \\
\hline Median (IQR) & $2(4)$ & $2(4)$ & \\
\hline Mean (SD) & $2.5(2.6)$ & $2.3(2.4)$ & \\
\hline \multicolumn{4}{|l|}{$\mathrm{IQR}=$ interquartile range. } \\
\hline \multicolumn{4}{|c|}{$\begin{array}{l}\text { a Calculated using } \chi^{2} \text { and Mann-Whitney } U \text { where applicable. } \\
\text { b Maximum score }=12 \text {. }\end{array}$} \\
\hline
\end{tabular}

Patient Enablement Index was similar for all groups (Table 4)

\section{DISCUSSION}

The introduction of CRP testing to assist antibiotic prescribing decisions in LRTI and rhinosinusitis consultations resulted in a reduction of antibiotic use directly after the index consultation and during 28-day follow-up without compromising recovery. Delayed prescriptions given to patients based on CRP assistance resulted in an absolute 50\% lower fill rate compared with delayed prescription in the control group. Patient satisfaction with care was higher when CRP was used during the consultation.

\section{Strengths and Limitations}

The number of patients assessed for eligibility but not recruited 
may have been higher than actually recorded by the family physicians, which is commonly seen in practice-based primary care studies. Yet, we are confident that this did not influence the results and generalizability of our findings. Unlike the previous CRP cluster randomized trial we performed ${ }_{1}^{17}$ risk of recruitment bias was lower in this trial, because patients were individually randomized with balanced baseline characteristics. Also, if we compare baseline CRP values and signs and symptoms, we find rates comparable to those recorded in previous LRTI and rhinosinusitis studies in family practice. ${ }^{17,18}$

We believe our inclusion criteria, drawn from prior studies in family practice settings, assembled a representative sample of adult patients with LRTI and rhinosinusitis. We included both these respiratory tract infections to increase our sample size and because they have the highest prescribing rates despite little evidence of benefit for most patients. As a result, however, our trial was not powered to detect differences in subgroups of the 2 separate conditions. Larger trials assessing the chosen approach may be warranted, also to provide more insight into the group using delayed prescriptions. This group of patients was relatively small in the present study.

We did not blind clinicians to treatment group because the physicians needed to know patients' CRP results to decide on appropriate clinical management. In contrast, strong allocation concealment was crucial to prevent tampering with the randomization. Another major strength of the study was the very high rate of patient follow-up and outcome assessment. It is increasingly recognized that clustering should be taken into account in individual RCTs. ${ }^{35}$ We performed a multilevel analysis as a sensitivity analysis, which accounted for variation at the level of the physician. The effect size remained significant, further strengthening the reliability of the shown effect on antibiotic use.

\section{Comparison With Other Studies-Delayed Prescribing}

Although our intervention was primarily aimed at assisting clinicians in antibiotic prescribing, the role of the patient in the outcome is crucial. A systematic review of 5 controlled trials investigating delayed prescribing for various respiratory tract infections showed a consistent reduction in antibiotic usage, with fill rates of delayed prescription ranging from $24 \%$ to $65 \% .{ }^{4}$ In our study, only a minority of patients in the CRP-assisted group actually used their delayed prescription $(23 \%)$, whereas in the control group $73 \%$ of those receiving a delayed prescription returned to fill it. In the end, delayed prescriptions led to significantly less antibiotic use in the CRP-assisted group, both after index consultation and during 28-day follow-up. We have incomplete data on the stated reasons for all patients filling delayed prescriptions, but of those patients with data, none indicated that their illness had deteriorated. This finding gives rise to the assumption that nonmedical reasons may be the driving force behind filling delayed prescriptions. We know that patients may pressure their physicians for unnecessary antibiotics either by asking directly or indirectly by the way they present their complaint. ${ }^{12,36,37}$ In our study, CRP testing and communicating the test results and its implications with the patient may have addressed patients' concerns and may have provided reassurance to a certain extent, resulting in fewer filled delayed prescriptions. Earlier research indicates that 93\% of patients having received a delayed prescription for upper respiratory tract infection would choose to receive one again. ${ }^{38}$

\section{Comparison With Other Studies-C-Reactive Protein Point-of-Care Testing}

A recent study comparing CRP with a clinical algorithm in the emergency department setting did not find an effect on antibiotic use for acute cough illness. ${ }^{39}$ This study was not performed in family practice, however. The authors suspect the Hawthorne effect of physicians changing prescribing behavior during trial monitoring, as the prescribing rate in control group was significantly lower than rates in periods before the trial. Also, chest radiographs were ordered in one-half the patients, whereas in Dutch family practice these radiographs are hardly used before the prescribing decision.

A CRP test result adds incremental information to the physicians' information obtained from medical history and physical examination. The relation of CRP with an infiltrate on chest radiography as a reference standard showed an area under the receiver operating characteristic (ROC) curve of 0.80 , even 0.85 for highquality diagnostic studies in family practice. ${ }^{16}$ The addition of CRP to a model based on signs and symptoms increased the area under the ROC curve from 0.70 to $0.90 .{ }^{15}$ In particular, a low CRP test result (less than $20 \mathrm{mg} / \mathrm{L}$ ), which was the case in more than 50\% of our patients, may be helpful in excluding antibiotic necessitating illness.

\section{Practice Implications and Future Research}

The interventions studied in this trial are additional tools to facilitate and support the respiratory tract infection consultation. Further work can evaluate whether it makes sense to confine the CRP strategy to cases of clinician doubt or strong patient demand. A delayed prescription, with an explanation on the natural 
course and indications when to use the antibiotic, may be a valuable tool for both physicians and patients that have intermediate CRP levels and associated clinical features. We have limited information on patients' views on delayed prescribing in our country, although in a nationwide public survey, we found that $40 \%$ of people would find it an acceptable strategy. ${ }^{40}$ Two commonly mentioned disadvantages of delayed prescribing are (1) the possibility of giving mixed messages about the purpose and benefits of antibiotics, and (2) considerable inconsistency and contradictory practices regarding its use. The former could be restricted by giving clear information on when to use it and when to reconsult. In this trial delayed prescriptions were handed out together with a short information sheet. Concerning the latter, CRP assistance may guide prescribing by identifying those patients who will probably get better without treatment but may need a safety net for the next few days in case of increasing illness severity.

Other biomarkers, such as procalcitonin, have been suggested. ${ }^{41}$ That procalcitonin is not available as a point-of-care test and that costs for measuring it are considerable make it undesirable for high-incidence common infections in family practice with low costs-per-illness episode. ${ }^{42} \mathrm{CRP}$ by contrast, is an office-based test with acceptable accuracy and costs (approximately $\$ 3$ to $\$ 5$ per point-of-care test) that is available to be integrated into the ambulatory management of respiratory infections.

CRP point-of-care testing to assist prescribing decisions_-including delayed prescribing_for LRTI and rhinosinusitis may be a useful strategy to decrease antibiotic use and increase patient satisfaction without comprising patient recovery, hence supporting antimicrobial stewardship.

To read or post commentaries in response to this article, see it online at http://www.annfammed.org/cgi/content/full/8/2/124.

Key words: Respiratory tract infection; C-reactive protein; family practice

Submitted April 28, 2009; submitted, revised, October 2, 2009; accepted October 23, 2009.

Author contributions: Jochen Cals and Rogier Hopstaken conceived the original idea for the study and were responsible for running the project. Sanne de Jong and Marjolein Schot contributed to the data collection and were responsible for daily management of the trial. All authors contributed to the design and implementation of the study. Jochen Cals wrote the first draft of the manuscript, all authors commented on it and all further revisions. Jochen Cals is guarantor for the paper. The corresponding author (J.C.) had full access to all the data in the study and takes responsibility for the integrity of the data and the accuracy of the data analysis.

Funding support: Orion Diagnostica, Espoo, Finland, funded this trial. Jochen Cals is supported by a grant of the Netherlands Organization for Health Research and Development (ZonMW) as an medical doctormedical research trainee.

Disclaimer: The funders had no role in the design and conduct of the study; collection, management, analysis, and interpretation of the data; and preparation, review, or approval of the manuscript.

Trial registration: Trialregister.nl Identifier: NTR1112

Acknowledgments: We are grateful for the support of Susanne Hanssen and Nienke Aaftink (Maastricht) in the data collection and logistics of the study. Nick Francis (Cardiff University) gave useful comments on the draft manuscript. We thank the participating family physicians and patients.

\section{References}

1. Hirschmann JV. Antibiotics for common respiratory tract infections in adults. Arch Intern Med. 2002;162(3):256-264.

2. De Sutter A, Lemiengre M, Van Maele G, et al. Predicting prognosis and effect of antibiotic treatment in rhinosinusitis. Ann Fam Med. 2006;4(6):486-493.

3. Smucny J, Fahey T, Becker L, Glazier R, Mclsaac W. Antibiotics for acute bronchitis. Cochrane Database Syst Rev. 2000;(4):CD000245.

4. Arroll B, Kenealy T, Kerse N. Do delayed prescriptions reduce antibiotic use in respiratory tract infections? A systematic review. Br J Gen Pract. 2003;53(496):871-877

5. Young J, De Sutter A, Merenstein D, et al. Antibiotics for adults with clinically diagnosed acute rhinosinusitis: a meta-analysis of individual patient data. Lancet. 2008;371(9616):908-914.

6. Holmes WF, Macfarlane JT, Macfarlane RM, Hubbard R. Symptoms, signs, and prescribing for acute lower respiratory tract illness. Br J Gen Pract. 2001;51(464):177-181.

7. Akkerman AE, Kuyvenhoven MM, van der Wouden JC, Verheij TJ. Prescribing antibiotics for respiratory tract infections by GPs: management and prescriber characteristics. Br J Gen Pract. 2005;55(511): 114-118.

8. Hopstaken RM, Stobberingh EE, Knottnerus JA, et al. Clinical items not helpful in differentiating viral from bacterial lower respiratory tract infections in general practice. J Clin Epidemiol. 2005;58(2):1 75-183.

9. Macfarlane J, Holmes W, Gard P, et al. Prospective study of the incidence, aetiology and outcome of adult lower respiratory tract illness in the community. Thorax. 2001;56(2):109-114.

10. Lindbaek M, Hjortdahl P, Johnsen UL. Randomised, double blind, placebo controlled trial of penicillin $\mathrm{V}$ and amoxycillin in treatment of acute sinus infections in adults. BMJ. 1996;313(7053):325-329.

11. Coenen S, Michiels B, Renard D, Denekens J, Van Royen P. Antibiotic prescribing for acute cough: the effect of perceived patient demand. Br J Gen Pract. 2006;56(524):183-190.

12. Little P, Dorward M, Warner G, Stephens K, Senior J, Moore M. Importance of patient pressure and perceived pressure and perceived medical need for investigations, referral, and prescribing in primary care: nested observational study. BMJ. 2004;328(7437):444.

13. Seamark DA, Backhouse SN, Powell R. Field-testing and validation in a primary care setting of a point-of-care test for C-reactive protein. Ann Clin Biochem. 2003;40(Pt 2):178-180.

14. Flanders SA, Stein J, Shochat G, et al. Performance of a bedside Creactive protein test in the diagnosis of community-acquired pneumonia in adults with acute cough. Am J Med. 2004;116(8):529-535.

15. Hopstaken RM, Muris JWM, Knottnerus JA, Kester ADM, Rinkens PELM, Dinant GJ. Contributions of symptoms, signs, erythrocyte sedimentation rate, and C-reactive protein to a diagnosis of pneumonia in acute lower respiratory tract infection. $\mathrm{Br} J$ Gen Pract. 2003;53(490):358-364. 
16. van der Meer V, Neven AK, van den Broek PJ, Assendelft WJ. Diagnostic value of $C$ reactive protein in infections of the lower respiratory tract: systematic review. BMJ. 2005;331(7507):26-29.

17. Cals JW, Butler CC, Hopstaken RM, Hood K, Dinant GJ. Effect of point of care testing for $C$ reactive protein and training in communication skills on antibiotic use in lower respiratory tract infections: cluster randomised trial. BMJ. 2009;338:b1374.

18. Bjerrum L, Gahrn-Hansen B, Munck AP. C-reactive protein measurement in general practice may lead to lower antibiotic prescribing for sinusitis. Br J Gen Pract. 2004;54(506):659-662.

19. Arroll B, Kenealy T, Goodyear-Smith F, Kerse N. Delayed prescriptions. BMJ. 2003;327(7428):1361-1362.

20. Spurling GK, Del Mar CB, Dooley L, Foxlee R. Delayed antibiotics for symptoms and complications of respiratory infections. Cochrane Database Syst Rev. 2004;(4):CD004417.

21. Little P, Rumsby K, Kelly J, et al. Information leaflet and antibiotic prescribing strategies for acute lower respiratory tract infection: a randomized controlled trial. JAMA. 2005;293(24):3029-3035.

22. Dowell J, Pitkethly M, Bain J, Martin S. A randomised controlled trial of delayed antibiotic prescribing as a strategy for managing uncomplicated respiratory tract infection in primary care. $\mathrm{Br} / \mathrm{Gen}$ Pract. 2001;51(464):200-205.

23. Cals JW, Butler CC, Dinant GJ. 'Experience talks': physician prioritisation of contrasting interventions to optimise management of acute cough in general practice. Implement Sci. 2009;4:57.

24. Cals JW, Hood K, Aaftink N, et al. Predictors of patient-initiated reconsultation for lower respiratory tract infections in general practice. Br J Gen Pract. 2009;59(567):761-764.

25. Lindbaek M, Hjortdahl P. The clinical diagnosis of acute purulent sinusitis in general practice-a review. Br J Gen Pract. 2002;52(479):491-495.

26. Young J, Bucher H, Tschudi P, Périat P, Hugenschmidt C, WelgeLüssen $A$. The clinical diagnosis of acute bacterial rhinosinusitis in general practice and its therapeutic consequences. J Clin Epidemiol. 2003;56(4):377-384.

27. Doig GS, Simpson F. Randomization and allocation concealment: a practical guide for researchers. J Crit Care. 2005;20(2):187-191, discussion 191-193.

28. Cals JW, Hopstaken RM, Butler CC, Hood K, Severens JL, Dinan GJ. Improving management of patients with acute cough by $C-$ reactive protein point of care testing and communication training (IMPAC3T): study protocol of a cluster randomised controlled trial. BMC Fam Pract. 2007;8:15.

29. Howie JG, Heaney DJ, Maxwell M, Walker JJ. A comparison of a Patient Enablement Instrument (PEI) against two established satisfaction scales as an outcome measure of primary care consultations. Fam Pract. 1998;15(2):165-171.
30. Kuyvenhoven M, van Essen G, Schellevis F, Verheij T. Management of upper respiratory tract infections in Dutch general practice; antibiotic prescribing rates and incidences in 1987 and 2001. Fam Pract. 2006;23(2):175-179.

31. Kuyvenhoven MM, van Balen FA, Verheij TJ. Outpatient antibiotic prescriptions from 1992 to 2001 in the Netherlands. J Antimicrob Chemother. 2003;52(4):675-678.

32. van Duijn HJ, Kuyvenhoven MM, Tiebosch HM, Schellevis FG, Verheij TJ. Diagnostic labelling as determinant of antibiotic prescribing for acute respiratory tract episodes in general practice. BMC Fam Pract. 2007;8:55.

33. Zhang J, Yu KF. What's the relative risk? A method of correcting the odds ratio in cohort studies of common outcomes. JAMA. 1998;280(19):1690-1691.

34. Altman DG, Schulz KF, Moher D, et al.; CONSORT GROUP (Consolidated Standards of Reporting Trials). The revised CONSORT statement for reporting randomized trials: explanation and elaboration. Ann Intern Med. 2001;134(8):663-694.

35. Lee KJ, Thompson SG. Clustering by health professional in individually randomised trials. BMJ. 2005;330(7483):142-144.

36. Scott JG, Cohen D, DiCicco-Bloom B, Orzano AJ, Jaen CR, Crabtree BF. Antibiotic use in acute respiratory infections and the ways patients pressure physicians for a prescription. J Fam Pract. 2001;50(10):853-858.

37. Arroll B, Goodyear-Smith F, Thomas DR, Kerse N. Delayed antibiotic prescriptions: what are the experiences and attitudes of physicians and patients? J Fam Pract. 2002;51(11):954-959.

38. Edwards M, Dennison J, Sedgwick P. Patients' responses to delayed antibiotic prescription for acute upper respiratory tract infections. Br J Gen Pract. 2003;53(496):845-850.

39. Gonzales R, Aagaard EM, Camargo CA, Jr. et al. C-reactive protein testing does not decrease antibiotic use for acute cough illness when compared to a clinical algorithm. J Emerg Med. 2008. Dec 16. [Epub ahead of print].

40. Cals JWL, Boumans D, Lardinois RJM, et al. Public beliefs on antibiotics and respiratory tract infections: an internet-based questionnaire study. Br J Gen Pract. 2007;57(545):942-947.

41. Briel M, Schuetz $P$, Mueller $B$, et al. Procalcitonin-guided antibiotic use vs a standard approach for acute respiratory tract infections in primary care. Arch Intern Med. 2008;168:2000-2007; discussion 2007-2008.

42. Cals JW, Metlay JP. Procalcitonin-based guidelines and lower respiratory tract infections. JAMA. 2010;303(5):418. 